\title{
A Colorful New Species of Albericus (Anura: Microhylidae) from Southeastern Papua New Guinea ${ }^{1}$
}

\author{
Fred Kraus ${ }^{2,3}$ and Allen Allison ${ }^{2}$
}

\begin{abstract}
We describe a new species of Albericus from the northern slope of Mt. Simpson, in the Owen Stanley Range of southeastern Papua New Guinea. The new species differs from all other known species of the genus in having pale blue or pale green dorsal coloration with red punctations (light metallic green and burnt orange in preservative). It is further distinguished from its congeners in its combination of oblique lores, granular skin with a few tubercles, broad head, large distance separating the external nares from the eyes, and in features of its call. We also provide comparative morphological measurements for most other species of Albericus to supplement the paucity of such data in original descriptions and to assist with future diagnoses of other new species.
\end{abstract}

The microhylid genus Albericus is endemic to New Guinea and includes 12 recognized species, 8 of which were described by Menzies (1999). The genus is characterized by small size (SV [body length from snout to vent] generally $<20 \mathrm{~mm}$ ); absence of clavicles, procoracoids, and omosternum; fifth toe longer than the third; disks of fingers broader than those of toes; and origin of $M$. depressor mandibulae mostly on the otic ramus of the squamosal and adjacent prootic (Burton and Zweifel 1995). Most species exhibit variegated patterns of drab browns, grays, and yellows. All but two species are endemic to Papua New Guinea, the country occupying the eastern half of New Guinea. The exceptions are Albericus variegatus, which is known only from the Upper Digul River in easternmost Papua (van Kampen 1923, Menzies 1999), and A. laurini, which was described recently from the Wandammen Peninsula in

\footnotetext{
${ }^{1}$ Supported in part by grant DEB-0103794 from the National Science Foundation. Manuscript accepted 15 March 2004.

${ }^{2}$ Bernice P. Bishop Museum, 1525 Bernice Street, Honolulu, Hawai'i 96817.

${ }^{3}$ Correspondence (phone: 808-848-4118; fax: $808-$ 847-8252; e-mail: fkraus@hawaii.edu).
}

Pacific Science (2005), vol. 59, no. 1:43-53

(C) 2005 by University of Hawai'i Press

All rights reserved the far west of the island (Günther 2000). Most species are known only from small samples and from type localities, so phylogenetic information is scarce. Menzies (1999), however, grouped species into three classes based on their calls. Six species were noted to have "buzz" or "squeak" calls, three species had "click" calls, and one species had a "peeping" or "bell-like" call. Günther's (2000) new species belongs to the first group, having a "buzz" or "squeak" call. The call of A. variegatus remains unknown.

During the course of conducting biotic surveys on Mt. Simpson, near the southeastern end of the Owen Stanley Range, we discovered a new species of Albericus that was immediately notable for its pulchritude. We describe that species here. We also provide mensural data for portions of the type series of most species to supplement the paucity of comparative information available from the original descriptions.

\section{MATERIALS AND METHODS}

Specimens were collected under relevant national and provincial permits, fixed in $10 \%$ buffered formalin, and transferred to $70 \%$ ethanol for storage. All measurements were made with an optical micrometer to the nearest $0.1 \mathrm{~mm}$. Measurements taken were body length, from snout to vent (SV); tibia length, from heel to outer surface of flexed knee (TL); distance from anterior corner of eye to 


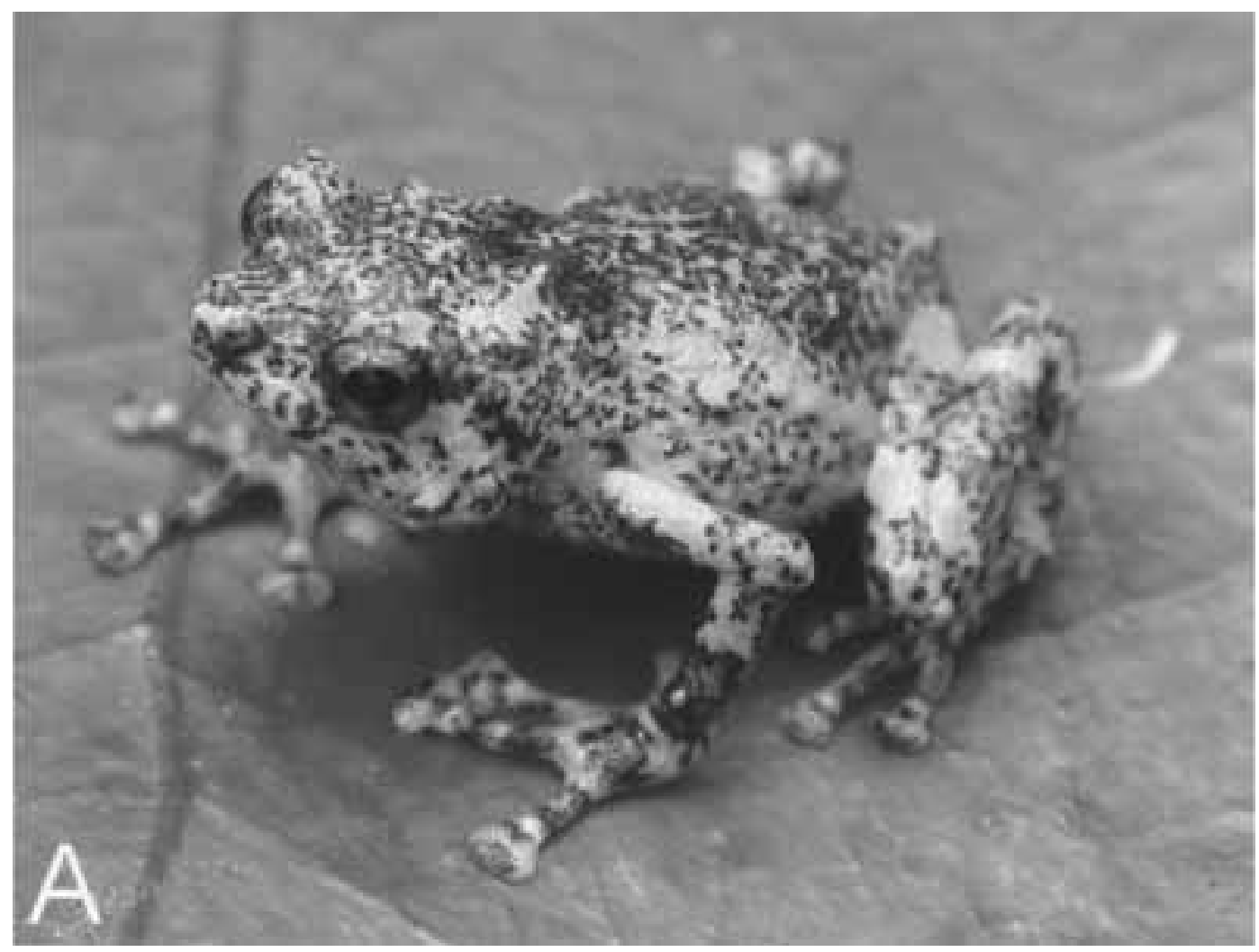

Figure 1. $(A)$ portrait and $(B)$ venter of Albericus sanguinopictus, paratype (врвм 17853), male, from 1,490-1,540 m, $\mathrm{N}$ slope of Mt. Simpson, Milne Bay Province, Papua New Guinea. Photograph by F. Kraus.

center of naris (EN); internarial distance, between centers of external nares (IN); distance from anterior corner of eye to tip of snout (SN); tympanum diameter (TY); diameter of eye (EY); head width at widest point (HW); head length, from tip of snout to posterior margin of tympanum (HL); hand length, from proximal edge of palm to tip of third finger (HandL); foot length, from proximal edge of sole to tip of fourth toe (FootL); arm length, from elbow to tip of third finger (ArmL); forearm length, ArmL - HandL (FA); width of the third finger disk (FD); width of the fourth toe disk (TD).

We recorded calls in the field using a microphone (Sennheiser ME66) and a cassette recorder (Sony Professional Walkman WMD6C). Call structure was analyzed using the computer program Avisoft-SAS Lab Pro (v4.23) [www.avisoft-saslab.com].
Type specimens of the new species are deposited in the Bernice P. Bishop Museum, Honolulu (врвм), and the Papua New Guinea National Museum and Art Gallery (PNGNM). Comparative data for Albericus variegatus, known only from the holotype, were taken from Menzies (1999); data for A. laurini were taken from Günther (2000); portions of the type series for all other species were examined directly and supplemented with additional data from Menzies (1999) when appropriate. Sex was determined by examination for vocal slits in males. Sex of presumptive females could not be verified by examination of gonads of the borrowed type specimens, so assignments as females should be viewed as tentative (see section on Specimens Examined).

Locality coordinates for the new species use Global Positioning System datum AUS 66. 


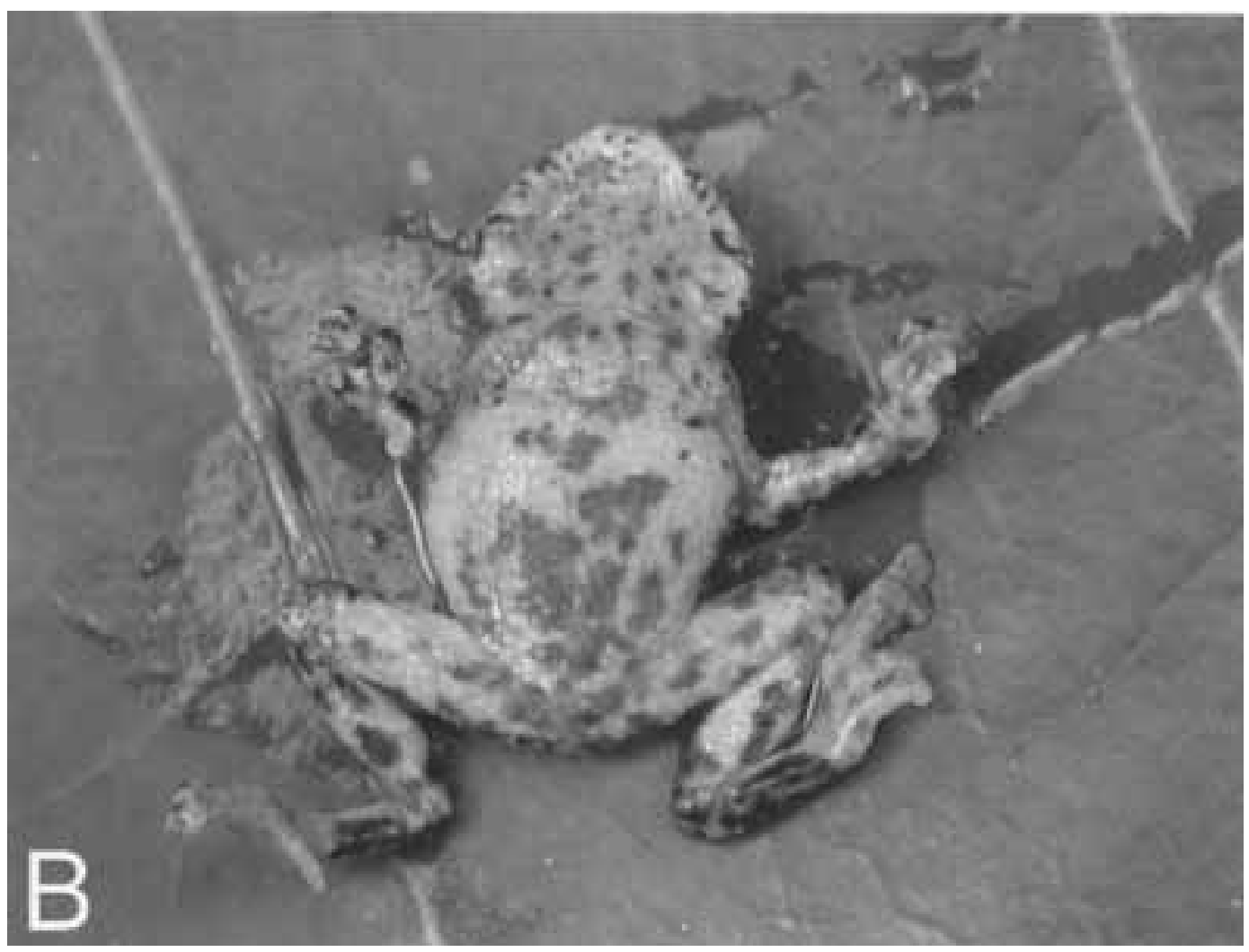

Figure 1. (continued)

Albericus sanguinopictus Kraus \& Allison, n. sp. Figures 1, 2

HOLOTYPE. врвм 17833 (field tag FK 7720), adult male, collected near Etakaba Creek, approximately $1 \mathrm{~km}$ SE Bunisi Village, $10.0245^{\circ} \mathrm{S}, 149.5947^{\circ} \mathrm{E}, 1,490-1,540 \mathrm{~m}, \mathrm{~N}$ slope of Mt. Simpson, Milne Bay Province, Papua New Guinea, by F. Kraus and B. Uruwa on 26 February 2003.

PARATYPES. ВРBM 17834-17855 and PNGNM 23897-23904, same data as holotype; врвм 17856, collected near Uga River, approximately $1 \mathrm{~km} \mathrm{~S}$ Bunisi Village, $10.0226^{\circ}$ S, $149.5920^{\circ}$ E, $1,400 \mathrm{~m}$, by F. Kraus on 27 February 2003; and врвм 17857, same data as holotype but collected by B. Uruwa on 27 February 2003. All paratypes are adult males. DIAGNosis. A medium-sized (15.4-17.4 $\mathrm{mm}$ ) species of Albericus having moderately long legs ( $\mathrm{TL} / \mathrm{SV}=0.41-0.47)$; long fore- arm (FA/SV $=0.28-0.35)$; broad head (HW/ $\mathrm{SV}=0.40-0.45, \quad \mathrm{HL} / \mathrm{HW}=0.76-0.86) ; \mathrm{a}$ relatively long snout $(\mathrm{EN} / \mathrm{SV}=0.098-0.118$, $\mathrm{IN} / \mathrm{SV}=0.076-0.090, \mathrm{EN} / \mathrm{IN}=1.1-1.5) ; \mathrm{a}$ medium-sized eye $(\mathrm{EY} / \mathrm{SV}=0.12-0.14, \mathrm{EY} /$ $\mathrm{SN}=0.74-0.88$ ); oblique lores; granular skin with a few large tubercles; snout blunt when viewed from above and truncate when viewed from side; dorsum pale blue or green, heavily covered with dark brown erose blotches and flecks and stippled with minute brick red punctations; venter paler bluish green with bright brick red or orange-red blotches; call an interminable series of clicks at an average rate of approximately 160 calls per minute and dominant frequency of 3,780-4,040 Hz.

Albericus sanguinopictus can be distinguished immediately from all other Albericus species on the basis of its pale blue or pale green ground color stippled with red dorsally and blotched with red ventrally (Figure 1); all 
other members of the genus are drab dorsally. The new species can be distinguished further from $A$. brunbildae, $A$. darlingtoni, $A$. fafniri, A. laurini, A. rhenaurum, A. siegfriedi, A. swanbildae, and $A$. tuberculus in having a "click" call instead of a "buzz," "squeak," or "peeping" call (cf. Menzies 1999 for classification). The call of $A$. variegatus is unknown; $A$. sanguinopictus can be distinguished from that species by its oblique lores, absence of basal webbing between toes 4 and 5, longer forearm (FA/SV $=0.25$ in $A$. variegatus), wider and longer head $(\mathrm{HW} / \mathrm{SV}=0.36, \mathrm{HL} /$ $\mathrm{HW}=0.74$ in $A$. variegatus), and broader snout (IN/SV $=0.075$ in $A$. variegatus).

Albericus gudrunae, A. gunnari, and A. valkuriarum are the only other species of Albericus having click calls. Albericus sanguinopictus can be further distinguished from $A$. gudrunae by its oblique lores, longer forearm (FA/ $\mathrm{SV}=0.26$ in A. gudrunae), and call consisting of an interminable series of clicks (short series of about 10 clicks in $A$. gudrunae); from $A$. gunnari by its broader head (HW/ $\mathrm{SV}=0.34-0.38$ in $A$. gunnari), venter lacking an intense blue blotch (present in $A$. gunnari), legs same color pattern as dorsum (banded dark and light blue in A. gunnari), slower call rate (240 calls per minute in $A$. gunnari), and higher dominant frequency of call (ca. 3,200 $\mathrm{Hz}$ in $A$. gunnari); and from $A$. valkuriarum by its granular dorsum having few tubercles (very warty in $A$. valkuriarum), longer forearm (FA/SV $=0.26-0.28$ in A valkuriarum), longer and narrower snout $(\mathrm{EN} / \mathrm{IN}=0.77$ $1.00, \quad \mathrm{EN} / \mathrm{SV}=0.082-0.097, \quad \mathrm{EY} / \mathrm{SN}=$ 0.84-1.00 in A. valkuriarum), faster call rate (up to 120 calls per minute in $A$. valkuriarum), and higher dominant frequency of call (ca. 2,400 Hz in A. valkuriarum).

DESCRIPTION OF HOLOTYPE. An adult male. Head wide $(\mathrm{HW} / \mathrm{SV}=0.44)$, wider than long $(\mathrm{HL} / \mathrm{SV}=0.36, \mathrm{HL} / \mathrm{HW}=0.81)$, with oblique loreal region; canthus rostralis rounded, nostrils much closer to tip of snout than to eyes; distance from external naris to eye considerably larger than internarial distance $(\mathrm{EN} / \mathrm{IN}=1.2, \mathrm{IN} / \mathrm{SV}=0.085, \mathrm{EN} /$ $\mathrm{SV}=0.10$ ); snout bluntly rounded when viewed from the side or from above, but with a narrow vertical keel at anterior tip; eyes moderately large $(\mathrm{EY} / \mathrm{SV}=0.13)$, pupil horizontal; interorbital distance approximately half again eyelid width; tympanum small $(\mathrm{TY} / \mathrm{SV}=0.061)$, its anterior and ventral margins raised, its dorsal and posterior margins largely hidden beneath overlying tubercular skin. Dorsum finely granular and with sparse tubercles, especially prominent above tympana and scapulae and more obscure elsewhere; supratympanic fold absent; lateral surfaces glandular or coursely granular; chin and throat finely granular, contrasting with coarsely granular abdominal surface. Fingers unwebbed, bearing disks with terminal grooves; relative lengths $3>4>2>1$. Finger disks approximately 2.5 times width of penultimate phalanges, except for the first finger disk, which is only approximately 1.5 times width of penultimate phalanx (Figure $2 A$ ). Subarticular tubercles low and indistinct; metacarpal tubercles absent although some skin thickening apparently indicated by lack of color in these areas. Toes unwebbed, bearing disks with terminal grooves; relative lengths $4>5>3>2>1$. Toe disks smaller than those of fingers $(\mathrm{FD} / \mathrm{TD}=1.18)$, approximately 1.5 times width of penultimate phalanges (Figure 2B). Subarticular tubercles lacking but with thicker, lighter skin in some areas; inner and outer metatarsal tubercles lacking. Hind legs moderately long (TL/ $\mathrm{SV}=0.47)$; arms long $(\mathrm{ArmL} / \mathrm{SV}=0.64$, $\mathrm{FA} / \mathrm{SV}=0.30)$.

In preservative, dorsal ground color bright, light metallic-green, widely flecked/blotched with dark brown, three dark markings concentrated into vague blotches middorsally, on head, forearm, and across center of thighs and tibiae; dark markings largely absent laterally. Superimposed on those green surfaces lacking the brown flecks are a large number of minute, burnt-orange punctations, especially numerous on the body, head, and face and less so on the limbs. A light metallic-green interorbital bar with vague borders present. Iris silver with a dark brown horizontal band anterior and posterior to pupil and narrow vertical bar above and below same, with irregular black marbling between these bars and bands. Chin and throat dirty white with a pale metallic-green cast and sparse black 


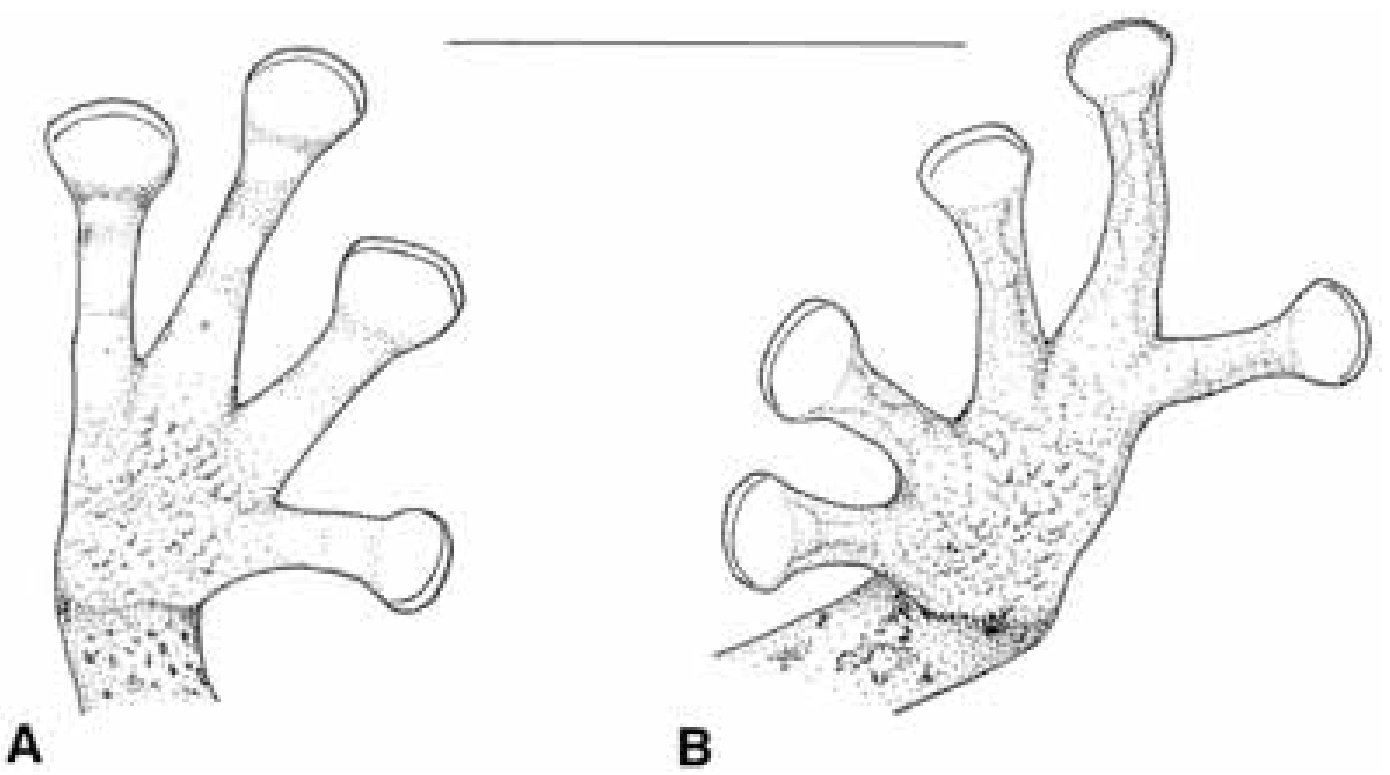

Figure 2. Views of $(A)$ hand and $(B)$ foot of Albericus sanguinopictus, holotype (врвм 17833). Scale bar $=5 \mathrm{~mm}$.

stippling; abdomen similar but green cast predominates and alternates with pale purple gray instead of dirty white. Undersides of legs pale purple-gray with pale metallic-green pigment sparsely scattered throughout. Palms and soles dirty white.

MEASUREMENTS (IN MM). SV $=16.5$, $\mathrm{TL}=7.8, \mathrm{HL}=5.9, \mathrm{HW}=7.3, \mathrm{IN}=1.4$, $\mathrm{EN}=1.7, \mathrm{SN}=2.7, \mathrm{EY}=2.1, \mathrm{TY}=1.0$, HandL $=5.6, \quad \mathrm{FA}=5.0, \quad \mathrm{ArmL}=10.6$, FootL $=6.9, \mathrm{FD}=1.3, \mathrm{TD}=1.1$.

COLOR IN LIFE. "Dorsum pale sky blue or porcelain blue with brown central blotch and many brick red punctations; venter pale sky blue with brick red splotches, especially on belly and legs, less on chin and throat. Soles and palms pale orange. Iris light purplebrown" (from field notes for врвм 17834). Most specimens in life were pale blue, but others (e.g., Figure 1, PNGNM 23901) were pale green instead. Degree of suffusion with the brick red punctations also varied, with most specimens as already described for врвм 17834, but PNGNM 23903 was noted to be heavily suffused with red above and below.

VARIATION. Most mensural characters do not vary greatly, although relative EN, TY,
$\mathrm{FD}$, and derivative ratios show the greatest range of values (Table 1). Tympanum diameter is often difficult to measure because of uncertainty regarding position of the posterior margin, and disk widths can vary substantially depending on quality of preservation of the specimen. Hence, wide variation in these two measurements is often observed and not unusual. The eye-naris distance is more reliably measured, and variation observed in this character is more confidently assigned to actual morphological variation in the sample rather than to artifact.

The color pattern of the sample at hand is remarkably uniform. The dark central blotch of coalesced flecking varies in being either more or less filled in with dark brown, providing greater or lesser contrast with the surrounding ground color. In one extreme, this middorsal region is largely green with brown outlining the margins of the blotch area; in the other extreme, the blotch is nearly uniformly brown. Most specimens have the middorsal blotch area well filled in with brown.

Two specimens have more of an overall yellow-orange appearance to the ground color 


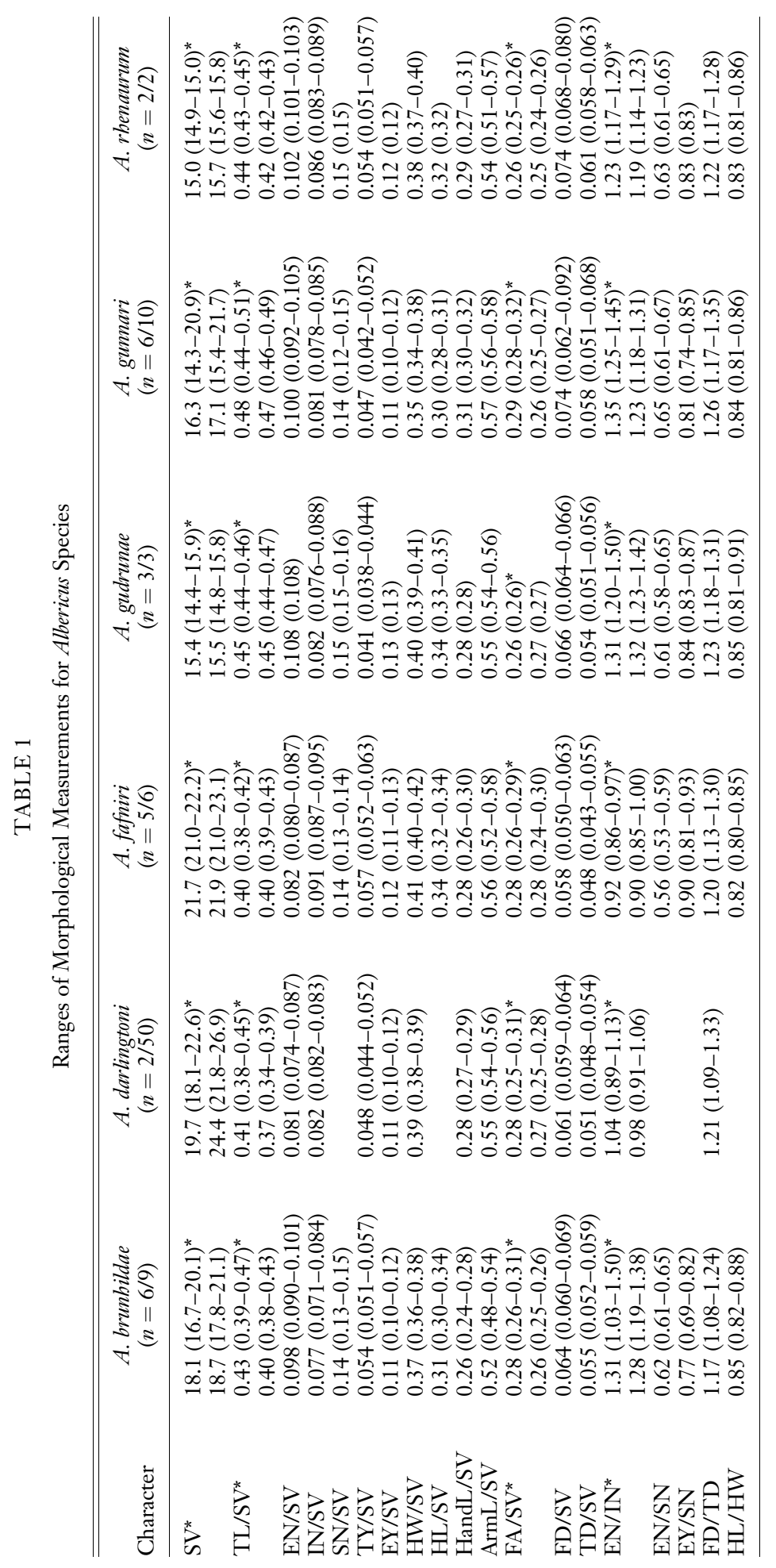




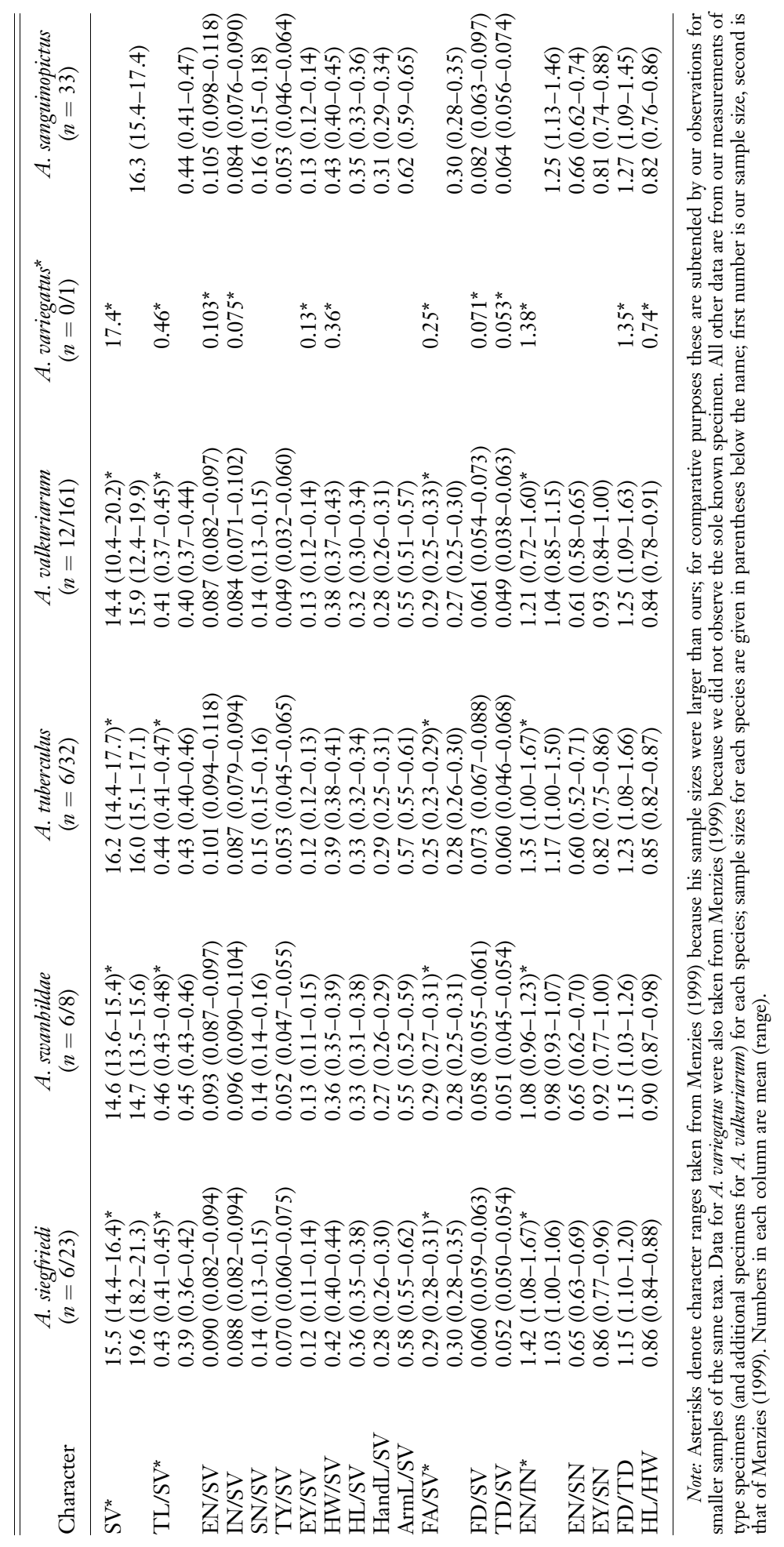




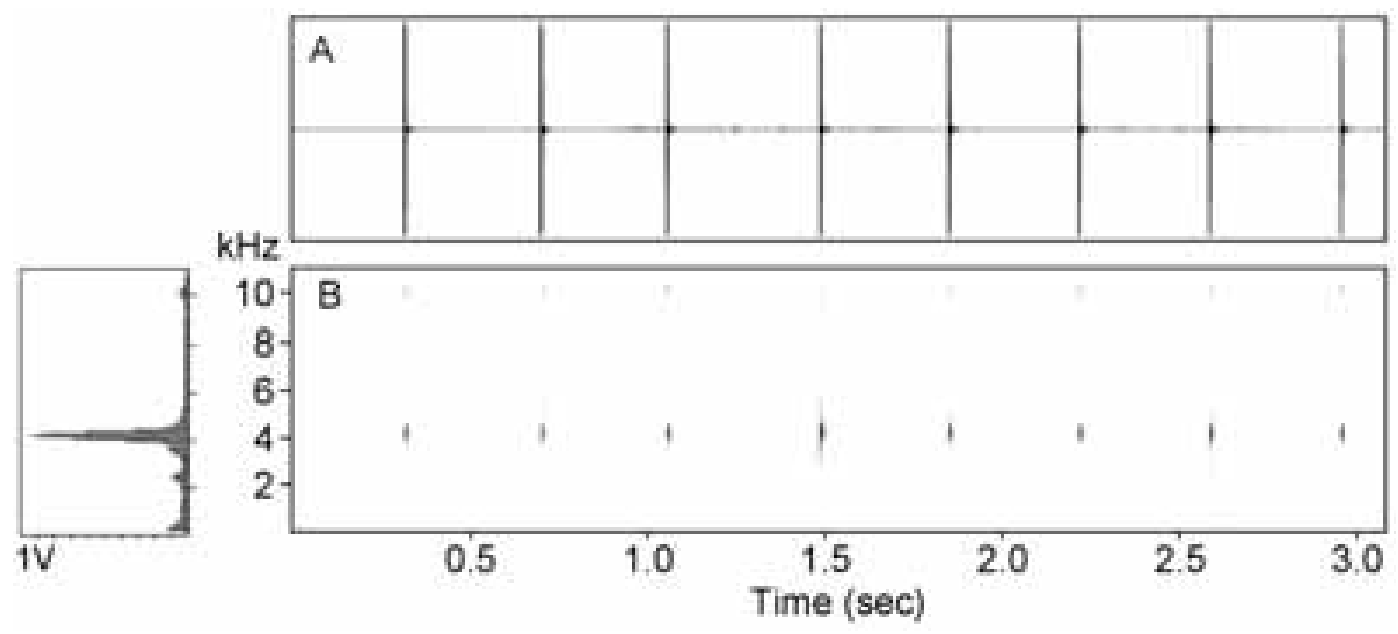

Figure 3. Call characteristics of Albericus sanguinopictus, paratype (врвм 17834). (A) Waveform of an eight-note sequence recorded at 2030 hours on 26 February 2003 at 1,490-1,540 m elevation, N slope of Mt. Simpson, Milne Bay Province, Papua New Guinea. Air temperature was $19.2^{\circ} \mathrm{C}$; $(B)$ Spectrogram of the preceding call. The power spectrum is shown to the left of the spectrogram. Recording by F. Kraus.

due to reduction of the green ground pigmentation, which lends heightened importance to the red-orange punctations in determining the general color appearance.

The dark ventral punctations are replaced by more obvious dark flecks across the chin, throat, and chest in approximately one-third of specimens.

The most striking color variation seen in the sample is the change that occurs after preservation. The light greenish blue ground color changes immediately to a bright, light metallic green, and the ventral orange-red spotting and orange on the soles and palms disappears. The ventral areas with orange-red spotting become a pale purple-gray; the soles and palms turn to dirty white. The dorsal punctations that are brick-red in life become burnt-orange in preservative.

CALL. The call consists of a single click sounding like the sharp striking of two pebbles together. We recorded calls from two individuals. врвм 17834 produced 692 calls during a 351-sec recorded segment; this recording was terminated without waiting for the frog to stop calling. The mean note length was 7.3 msec (range 5.7-8.1). The duration between calls varied from 0.025 to $18 \mathrm{sec}$. The waveform of eight calls is shown in Figure $3 A$. The dominant frequency is $4,040 \mathrm{~Hz}$ (Figure 3B). This segment is representative of a period of intense calling activity in which there were about 2.7 calls per second (162 calls per minute). The call characteristics of the second individual (врвм 17833) were similar to that of врвм 17834 , although it had a longer call note of $9.0 \mathrm{msec}$ (range $8.1-10.1 ; n=224$ ) and a lower dominant frequency of $3,785 \mathrm{~Hz}$. The internote duration ranged from 0.027 to $1.5 \mathrm{sec}$. This individual produced 2.6 calls per second (156 calls per minute) during an intense calling period. Both frogs were recorded at the same locality within $30 \mathrm{~min}$ of one another. The air temperature was $19.2^{\circ} \mathrm{C}$ for both recordings.

The call of Albericus sanguinopictus differs from that of $A$. gudrunae in being a long series (up to $5+$ min, $700+$ calls) instead of a short series of approximately 10 calls (Menzies 1999). Albericus sanguinopictus calls at a faster rate than $A$. valkuriarum and at a slower rate than $A$. gunnari; its dominant frequency is higher than that of either species (Menzies 1999).

ECOLOGical notes. The habitat at the type locality consists of lower montane forest (Paijmans 1975, 1976). All specimens were collected perching on leaves and stems $1-3 \mathrm{~m}$ 


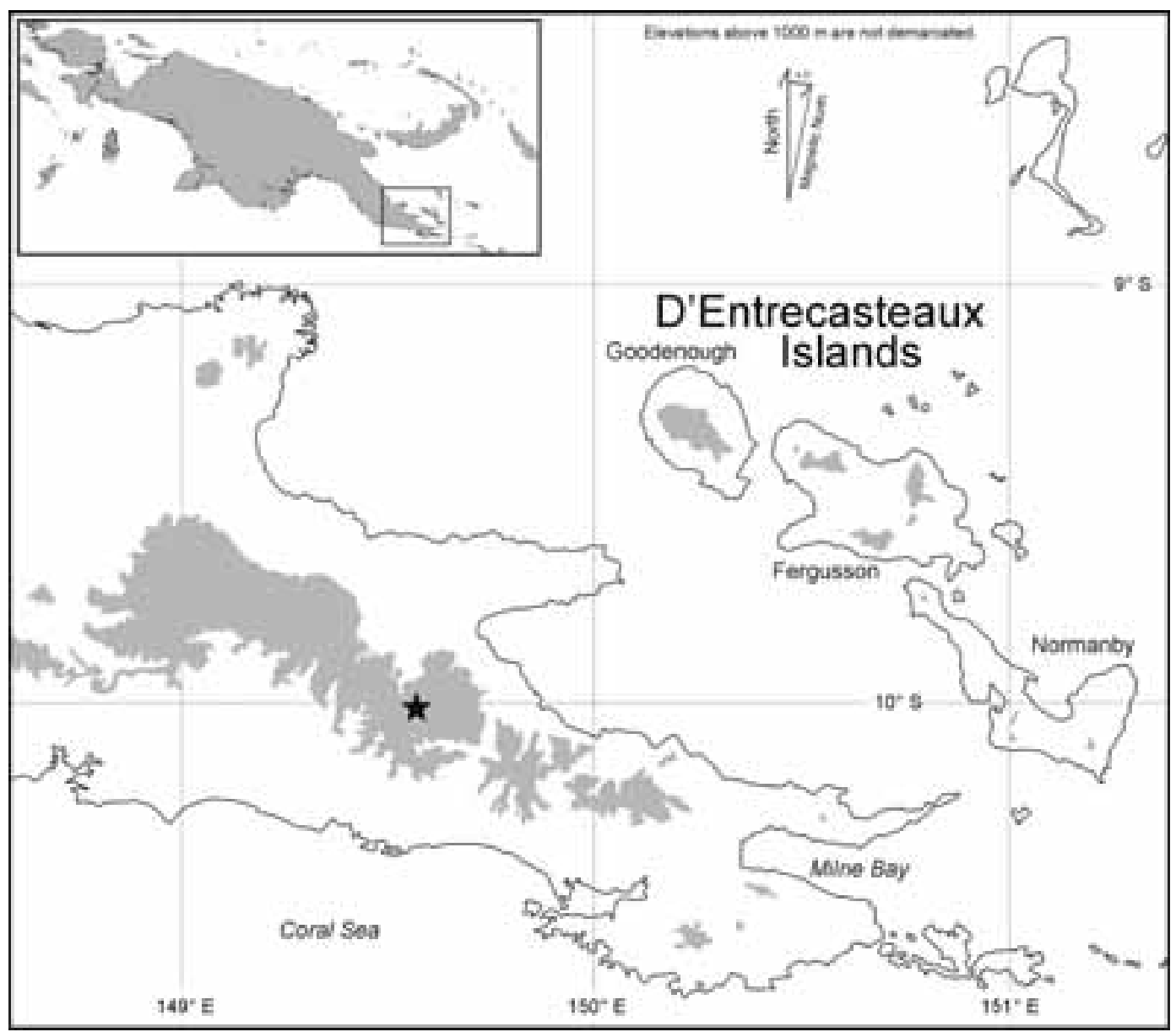

Figure 4. Map of southeastern New Guinea and adjacent islands, showing the type locality of Albericus sanguinopictus (star).

above the forest floor at $1,400-1,500 \mathrm{~m}$ elevation while calling at night. The frogs were abundant but spotty in distribution and were not easily distracted when calling.

eтYMOLOGY. The name is a masculine adjective formed from combining the Latin noun for blood, "sanguis," with the Latin adjective for painted, "pictus," and refers to the distinctive red blotching and punctations that characterize the species.

distribution. Known only from the type locality (Figure 4). The species is likely to range throughout the lower montane forests surrounding Mt. Simpson, but it is uncertain whether it will be found in similar forests surrounding Mt. Dayman and Mt. Suckling to the north because of the intervening strip of lower-elevation grassland separating Mt. Simpson from the latter two mountains (Paijmans 1975, SE sheet).

\section{DISCUSSION}

Species of Albericus have been relatively poorly diagnosed from each other morphologically, with reliance placed primarily on call type combined with a few important mensural ratios. For example, in describing $A$. brunbildae, Menzies (1999) noted that "No morphological characters distinguish it abso- 
lutely from any other species." However, we find that some characters not discussed by Menzies (1999) (e.g., EN/SV, IN/SV, TY/ $\mathrm{SV}, \mathrm{EN} / \mathrm{SN}$ ) do provide discrimination of $A$. brunbildae from some other species, at least based on the modest sample sizes available to us, and the same appears true for other species as well. No doubt some overlap in many of these characters will be found as sample sizes increase, but these results suggest additional variables that may, in concert, prove useful for helping to distinguish new species from the named members of this genus. To that end, we provide data in Table 1 for a broader array of morphological attributes than are currently available in the literature.

No such problem hinders recognizing Albericus sanguinopictus, whose identity is apparent at a glance. The colorful blue (or green) and red pattern distinguishes this species from all known congeners. The only other species noted to have bright colors, $A$. gunnari, has a large blue blotch on the abdomen and dark blue bands on the hind limbs (Menzies 1999; F.K., pers. obs.). In addition to having these brightly colored features, $A$. gunnari is also one of the few Albericus species with a click call and is the species in closest geographical proximity to $A$. sanguinopictus. Possibly, these features indicate a close relationship between the two.

In comparing Albericus sanguinopictus with the other click-callers, A. gudrunae, A. gunnari, and $A$. valkuriarum, we noted in our diagnosis that $A$. sanguinopictus differs from these relatives in a variety of call parameters, including call-series duration, call rate, and dominant frequency. In comparing call rates among these species, our diagnosis has relied on the verbal descriptions provided by Menzies (1999). For both $A$. gunnari and $A$. valkuriarum, the call rates noted in his text $(240$ per minute and 120 per minute, respectively) appear to contrast with those shown in his figures 17 and 18 in a manner suggesting that the figures for those two species were inadvertently transposed. Alternately, it is possible that the figures are correctly assigned to species but the numbers provided in the text were transposed. In either event, $A$. sanguinopictus still remains distinct from both species in this character, but it remains ambiguous exactly how the differences are to be assigned.

In investigating comparative material of the other named species of Albericus, we found our measurements to be in close accord with those of Menzies (1999) for the characters we both measured in all except one instance. That exception is for the sample of $A$. siegfriedi, of which we were able to examine 6 of his total sample of 23 specimens. In this case, our measurements for SV and EN/IN exhibit no overlap whatsoever with the values reported by Menzies (1999). The SV measurements, of course, could vary depending on preservative conditions, although it seems odd for them to gain so much in length. We do note that the specimens we examined are uniformly bright red, similar to maraschino cherries, and this may connote that they have been exposed to some unusual substance that accounts for the size discrepancy, although, aside from the odd color, the specimens appear to be in good shape. The situation with the EN/IN ratio cannot be thus explained. Careful reexamination of this character shows that the EN and IN measurements are very similar in all specimens we examined and do not vary by the large degree reported by Menzies (1999). We can only surmise that this discrepancy reflects a typographical mistake in that paper. This is important because $A$. siegfriedi was distinguished from $A$. darlingtoni and $A$. fafniri, in part, on the basis of EN/IN ratio. This distinction appears no longer to separate $A$. siegfriedi from $A$. darlingtoni.

One final point requires mention. Included in a long list of paratypes of Albericus valkuriarum are two specimens (UPNG 9442-9443) that are either Cophixalus kaindiensis or $C$. parkeri (resolution of which requires call information and cannot be determined from preserved specimens). We have not been able to examine all of the type series for that species, but have briefly viewed several dozen other paratypic specimens, all of which are Albericus and morphologically homogeneous. Hence, it seems likely that the two Cophixalus specimens are included in the paratypic list of Menzies (1999) due to a typographical numbering error. 


\section{SPECIMENS EXAMINED}

All specimens examined proved to be male except for one $A$. brunbildae, one $A$. darlingtoni, and five $A$. siegfriedi, which are inferred to be female (see those entries).

Albericus brunbildae. Papua New Guinea: Madang Province: Mambimap, Adelbert Mountains, 1,400 m (UPNG 7192, holotype; 7188,7189 [female], 7191, 7193, 7195, paratypes).

Albericus darlingtoni. Papua New Guinea: Chimbu Province: Toromanbanau, Bismarck Range, 2,300 m (AMNH 58666 [female], 58667, paratypes).

Albericus fafniri. Papua New Guinea: Southern Highlands Province: $16 \mathrm{~km} \mathrm{NE}$ Mendi, 2,500 m (UPNG 5562, holotype; 55635566, paratypes).

Albericus gudrunae. Papua New Guinea: Madang Province: near Kowat, Adelbert Mountains, $900 \mathrm{~m}$ (UPNG 8124, holotype; 8123,8125 , paratypes).

Albericus gunnari. Papua New Guinea: Central Province: Aieme Creek, 450 m (UPNG 5240, holotype; 4153-4154, 5241-5243, paratypes).

Albericus rhenaurum. Papua New Guinea: Western Province: Moiyokabip, 1,200 m (UPNG 4417, holotype; 4418, paratype).

Albericus siegfriedi. Papua New Guinea: Chimbu Province: Mt. Elimbari, 2,500 m (UPNG 3480, holotype; 3483-3484, 3487, 3489, 3501, paratypes [all female]).

Albericus swanbildae. Papua New Guinea: Southern Highlands Province: $16 \mathrm{~km} \mathrm{NE}$ Mendi, 2,500 m (UPNG 5572, holotype; 55735574, 5576, 5591-5592, paratypes).

Albericus tuberculus. Papua New Guinea: Madang Province: Kaironk, Schrader Mountains, $1,830 \mathrm{~m}$ (UPNG 3304, 3306, 3315); Western Province: Mt. Akrik, 1,625 m (UPNG 8441, holotype); Moiyokabip, 1,520 m (UPNG 4411-4412).

Albericus valkuriarum. Papua New Guinea: Morobe Province: Hidden Valley, $14 \mathrm{~km} \mathrm{SSE}$ Wau, 2,600 m (UPNG 9454, holotype; 74537455 , paratypes); summit Mt. Kaindi, 2,3502,360 m (врвм 5153, 9349, 9519); Wau, Salamaua Track (врвм 14067); Mt. Missim,
2,400 m (врвм 14071); Bulldog Road, $50 \mathrm{~km}$ SE Wau (врвм 14080-14082, 14084).

Cophixalus (C. kaindiensis or C. parkeri). Papua New Guinea: Morobe Province: Hidden Valley, $14 \mathrm{~km}$ SSE Wau, 2,600 m (UPNG 9442-9443, paratypes of $A$. valkuriarum).

\section{ACKNOWLEDGMENTS}

We thank C. Kishinami and K. Igeta for specimen processing and documentation; R. Siagadan for loan of specimens; B. Evans for help producing the figures; F. Malesa, B. Uruwa, Dage, Genta Sr., Genta Jr., Munda, Peter, Tanunu, and many other inhabitants of the Bunisi area for field assistance; and Aussiya, H. Kurage, D. Mitchell, B. Seta, and the people of Bunisi for providing logistical assistance and/or permission to work in the Mt. Simpson area. We thank the PNG National Museum and Art Gallery for providing incountry collaborative assistance, and the Department of Environment and Conservation, National Research Institute, and Milne Bay Provincial Government for permission to conduct this research.

\section{Literature Cited}

Burton, T. C., and R. G. Zweifel. 1995. A new genus of genyophrynine microhylid frogs from New Guinea. Am. Mus. Novit. 3129:1-7.

Günther, R. 2000. Albericus laurini species nova, the first record of the genus Albericus (Anura, Microhylidae) from the west of New Guinea. Mitt. Mus. Naturkunde Berl. Zool. Reihe 76:167-174.

Menzies, J. I. 1999. A study of Albericus (Anura: Microhylidae) of New Guinea. Aust. J. Zool. 47:327-360.

Paijmans, K. 1975. Vegetation of Papua New Guinea. Aust. C.S.I.R.O. Land Res. Ser. 35:1-25 + 4 maps.

1976. New Guinea vegetation. Australian National University Press, Canberra.

van Kampen, P. N. 1923. The Amphibia of the Indo-Australian Archipelago. E. J. Brill, Leiden, Netherlands. 
